\title{
BMJ
}

\section{Information sheets for patients with acute chest pain: randomised controlled trial}

${ }^{1}$ Northern General Hospital,

Sheffield Teaching Hospitals,

NHS Foundation Trust, Sheffield

S5 7AU

${ }^{2}$ Health Services Research, School of Health and Related Research, University of Sheffield

${ }^{3}$ Department of Information Studies, University of Sheffield

${ }^{4}$ Department of Psychiatry, University of Oxford Correspondence to: J Arnold Jane.Arnold@sth.nhs.uk

Cite this as: $B M J$ J 2009;338:b54 doi:10.1136/bmj.b541

\author{
Jane Arnold, chest pain assessment sister, ${ }^{1}$ Steve Goodacre, professor of emergency medicine, ${ }^{2}$ \\ Peter Bath, senior lecturer in health informatics, ${ }^{3}$ Jonathan Price, clinical tutor in psychiatry ${ }^{4}$
}

\author{
ABSTRACT \\ Objectives To determine whether providing an \\ information sheet to patients with acute chest pain \\ reduces anxiety, improves health related quality of life, \\ improves satisfaction with care, or alters subsequent \\ symptoms or actions.
}

Design Single centre, non-blinded, randomised controlled trial.

Setting Chest pain unit of an emergency department. Participants 700 consecutive patients with acute chest pain and no clear diagnosis at initial presentation. Interventions After a diagnostic assessment patients were randomised to receive either standard verbal advice or verbal advice followed by an information sheet.

Main outcome measures The primary outcome was anxiety (hospital anxiety and depression scale). Secondary outcomes were depression (hospital anxiety and depression scale), health related quality of life (SF36), patient satisfaction, presentation with further chest pain within one month, lifestyle change (smoking cessation, diet, exercise), further information sought from other sources, and planned healthcare seeeking behaviour in response to further pain.

Results 494 of 700 (70.6\%) patients responded. Compared with those receiving standard verbal advice those receiving advice and an information sheet had lower mean hospital anxiety and depression scale scores for anxiety $(7.61 \mathrm{v} 8.63$, difference $1.02,95 \%$ confidence interval 0.20 to 1.84$)$ and depression ( $4.14 v 5.28$, difference $1.14,0.41$ to 1.86 ) and higher scores for mental health and perception of general health on the SF-36. The information sheet had no significant effect on satisfaction with care, subsequent symptoms, lifestyle change, information seeking, or planned actions in the event of further pain.

Conclusions Provision of an information sheet to patients with acute chest pain can reduce anxiety and depression and improve mental health and perception of general health but does not alter satisfaction with care or other outcomes.

Trial registration Current Controlled Trials ISRCTN85248020.

\section{INTRODUCTION}

Chest pain is responsible for around 700000 emergency department attendances each year in England and Wales. ${ }^{1}$ Many of these patients have no immediately obvious cause for their pain and require diagnostic assessment, the results of which need to be carefully communicated to the patient. Despite thorough diagnostic assessment many patients have further episodes of chest pain, often associated with anxiety and uncertainty about diagnosis. ${ }^{2-4}$ This can have an important impact on quality of life. ${ }^{4}$

Written information could help to tackle problems with communication. Information sheets have been developed for use in the cardiology outpatient setting and used to assist with communication. ${ }^{5}$ We have adapted these information sheets for use by patients with acute chest pain in the emergency department by undertaking 30 semistructured face to face interviews to explore patients' perceptions of the information sheets. ${ }^{6}$ Further refinement led to four separate information sheets for patients in the following categories after diagnostic assessment: definite angina, definite benign non-cardiac chest pain, uncertain cause requiring further cardiology investigation, and uncertain cause suitable for expectant ("wait and see") management (see web extra appendices).

We determined whether provision of an information sheet could improve care for patients who had received diagnostic assessment for acute chest pain. Specifically, we determined whether the information sheet would reduce anxiety, improve health related quality of life and satisfaction with care, and alter subsequent symptoms of chest pain, lifestyle, information seeking behaviour, and planned actions in the event of further pain.

\section{METHODS}

We undertook a non-blinded randomised controlled trial to compare verbal advice alone with verbal advice augmented with an information sheet in patients assessed for acute chest pain. The trial was carried out in the emergency department of a 1100 bed urban teaching hospital. Specialist chest pain nurses provided rapid diagnostic assessment for acute coronary syndrome using biochemical cardiac marker testing (creatine kinase $\mathrm{MB}$ (mass) levels at baseline and at least two hours later, and troponin I levels at least six hours after worst symptoms) and exercise treadmill 
testing for selected cases. Emergency doctors were responsible for overseeing decision making, whereas the chest pain nurses were responsible for diagnostic testing and treatment. The doctor typically communicated the main diagnostic impression and outlined the management plan to the patient. The chest pain nurses then provided more detailed information and undertook further communication.

We planned to recruit 700 consecutive patients who had been investigated for suspected acute coronary syndrome. Patients were investigated if they had chest pain of possible cardiac origin, were aged over 25 , had no changes for acute coronary syndrome on a diagnostic electrocardiogram, had no suspected life threatening non-cardiac disease, and did not have known coronary heart disease presenting with recurrent or prolonged episodes of cardiac-type chest pain.

Eligible patients were identified by the chest pain nurses, who excluded patients who had previously participated in the trial and those who were unable to read or comprehend the trial documentation. After providing written, informed consent the patients were randomly allocated to receive either standard verbal advice or verbal advice followed by an information sheet relevant to their diagnosis at discharge. Allocation was determined by a block randomisation sequence, with variable block length and stratified by the four different information sheets, that was generated by the Sheffield Clinical Trials Research Unit. Randomisation was implemented using consecutively numbered, sealed, opaque envelopes with corresponding numbered consent forms. The chest pain nurses were unaware of allocation until after the patient was recruited to the trial. The nurses confirmed recruitment

\begin{tabular}{|c|c|}
\hline \multicolumn{2}{|c|}{ Eligible patients with acute chest pain $(n=869)$} \\
\hline & $\begin{array}{l}\text { Excluded }(n=167) \text { : } \\
\text { No factsheet applicable }(n=50) \\
\text { Did not complete chest pain protocol }(n=37) \\
\text { Declined to participate }(n=32) \\
\text { Unable to read English }(n=27) \\
\text { Cognitive impairment }(n=19) \\
\text { Missing reason }(n=2)\end{array}$ \\
\hline \multicolumn{2}{|c|}{ Randomised $(n=702)$} \\
\hline \multirow[b]{2}{*}{$\downarrow$} & Withdrawn, consent not signed $(n=2)$ \\
\hline & $\downarrow$ \\
\hline \multirow[t]{2}{*}{$\begin{array}{l}\text { Allocated to verbal advice followed by } \\
\text { information sheet }(n=349) \text { : } \\
\text { Benign }(n=81) \\
\text { Uncertain, expectant follow-up }(n=228) \\
\text { Uncertain, cardiology follow-up }(n=30) \\
\text { Angina }(n=10)\end{array}$} & $\begin{array}{l}\text { Allocated to verbal advice only }(n=351) \text { : } \\
\text { Benign }(n=81) \\
\text { Uncertain, expectant follow-up }(n=230) \\
\text { Uncertain, cardiology follow-up }(n=31) \\
\text { Angina }(n=9)\end{array}$ \\
\hline & \multirow[b]{2}{*}{$\downarrow$} \\
\hline$\downarrow$ & \\
\hline $\begin{array}{l}\text { Questionnaires returned }(n=246) \text { : } \\
\text { 1st mailing }(n=116) \\
\text { 2nd mailing }(n=88) \\
\text { 3rd mailing }(n=42) \\
\text { Undelivered }(n=1)\end{array}$ & $\begin{array}{l}\text { Questionnaires returned }(n=248) \text { : } \\
\text { 1st mailing }(n=137) \\
\text { 2nd mailing }(n=70) \\
\text { 3rd mailing }(n=41) \\
\text { Undelivered }(n=3)\end{array}$ \\
\hline
\end{tabular}

Patient flow through trial of each patient by telephone to the lead investigator (JA), who accounted for all envelopes.

Intervention took place after diagnostic assessment was complete and the patient's management plan had been formulated. On the basis of the diagnostic information obtained, the chest pain nurses decided which of the four information sheets was most appropriate for each patient. This decision was recorded before randomisation. After randomisation, patients in both the intervention and the control groups received standard verbal advice from the chest pain nurses. After advice, patients allocated to the intervention group were given the appropriate information sheet to read and take away. The chest pain nurses answered any queries about the information but did not talk through the sheet with the patients.

We collected basic data on all enrolled patients, including sex, age, ethnic origin, and risk factors for coronary heart disease. One month after recruitment all patients were sent a questionnaire by post consisting of the hospital anxiety and depression scale, the SF-36 health related quality of life survey, a patient satisfaction survey, and a brief questionnaire asking about severity and duration of any symptoms related to chest pain, any attempts at lifestyle change (smoking cessation, dietary change, and exercise), whether the patient sought information about their symptoms from other sources, and what actions the patient would take in the event of further chest pain. Questionnaires were resent to non-responders at six and eight weeks. Once responses had been received all participants in the control group were sent a copy of the information sheet most appropriate to their discharge diagnosis.

The primary outcome was scores on the anxiety subscale of the hospital anxiety and depression scale. Secondary outcomes included the depression score on the hospital anxiety and depression scale; SF-36 scores; patient satisfaction; presentation with further chest pain within one month; attempted smoking cessation, dietary change, or increased exercise; seeking further information from a variety of sources; and planned healthcare seeeking behaviour in response to further pain.

The hospital anxiety and depression scale comprises a self screening questionnaire with 14 questions, which was developed and validated for measuring symptoms of anxiety and depression in the outpatient setting. ${ }^{7}$ It produces scores on two subscales (anxiety and depression) ranging from 0 to 21 . Scores of 0-7 indicate no depression or anxiety, 8-10 indicate mild symptoms, 11-14 indicate moderate symptoms, and 15-21 indicate severe symptoms. The SF-36 is a self screening questionnaire consisting of 36 questions about health related quality of life. ${ }^{8}$ It produces scores between 0 and 100 for eight dimensions of quality of life, where 0 is the lowest quality of life and 100 the highest. The patient satisfaction survey was developed from the Group Health Association of America consumer satisfaction survey ${ }^{9}$ and consists of 12 questions relating to different aspects of care, each with a five point Likert scale response allowing ratings of poor (1 point), satisfactory 
Table 1|Baseline characteristics of patients with acute chest pain randomised to receive verbal advice followed by an information sheet (intervention) or verbal advice alone. Values are numbers (percentages) unless stated otherwise

\begin{tabular}{lccc} 
Variables & $\begin{array}{c}\text { Intervention group } \\
(\mathrm{n}=349)\end{array}$ & $\begin{array}{c}\text { Control group } \\
(\mathrm{n}=351)\end{array}$ & $\begin{array}{c}\text { Total } \\
(\mathrm{n}=700)\end{array}$ \\
Mean (SD) age (years) & $48.3(11.8)$ & $48.9(11.2)$ & $48.6(11.5)$ \\
\hline Men & $214(61)$ & $217(62)$ & $431(61.6)$ \\
\hline Diagnostic group receiving information sheet: & $81(23)$ & $81(23)$ & $162(23)$ \\
\hline Benign non-cardiac chest pain & $228(65)$ & $230(66)$ & $458(65)$ \\
\hline Chest pain uncertain, no follow-up & $30(9)$ & $31(9)$ & $61(9)$ \\
\hline Chest pain uncertain, referred to cardiology & $10(3)$ & $9(3)$ & $19(3)$ \\
\hline Angina & & $101(29)$ & $179(25)$ \\
\hline Risk factors: & $78(22)$ & $50(14)$ & $114(16)$ \\
\hline Smoker & $64(18)$ & $20(6)$ & $40(6)$ \\
\hline Former smoker & $20(6)$ & $84(24)$ & $160(23)$ \\
\hline Diabetes & $76(22)$ & $73(21)$ & $136(19)$ \\
\hline Hypertension & $63(18)$ & $142(40)$ & $282(40)$ \\
\hline Hyperlipidaemia & $140(40)$ & $10(3)$ & $20(3)$ \\
\hline Family history & $10(3)$ & & \\
\hline Previous history of coronary heart disease & & & \\
\hline
\end{tabular}

(2), good (3), very good (4), and excellent (5). It has been used in patients with acute chest pain..$^{10}$ The remaining questions on the survey were designed for this study and piloted on appropriate patients to ensure basic comprehensibility.

We planned to recruit 700 participants (350 in each arm) over 15 months and anticipated a $70 \%$ response rate to the questionnaire, giving usable data for around 500 patients. This would provide $80 \%$ power to detect a one point change in the anxiety score on the hospital anxiety and depression scale $(\alpha 0.05)$ assuming a standard deviation of four points. ${ }^{1011}$

SPSS version 15 was used to analyse data. We analysed all available cases as randomised using $\chi^{2}$ tests to compare dichotomous outcomes, $t$ tests to compare continuous outcomes, and Kruskal Wallis tests to compare ordered categorical outcomes - that is, categorised scores on the hospital anxiety and depression

Table 2|Comparison of anxiety and depression by score categories (not scores) on hospital anxiety and depression scale (HADS) in patients with acute chest pain randomised to receive verbal advice followed by an information sheet (intervention) or verbal advice alone. Values are numbers (percentages) unless stated otherwise

\begin{tabular}{|c|c|c|c|}
\hline HADS subscales & Control group & Intervention group & P value* \\
\hline \multicolumn{4}{|l|}{ Anxiety: } \\
\hline None (0-7) & $103(43.5)$ & $130(54.6)$ & \multirow{4}{*}{0.009} \\
\hline Mild (8-10) & $48(20.3)$ & $42(17.6)$ & \\
\hline Moderate (11-14) & $53(22.4)$ & $47(19.7)$ & \\
\hline Severe (15-21) & 33 (13.9) & $19(8.0)$ & \\
\hline \multicolumn{4}{|l|}{ Depression: } \\
\hline None (0-7) & $172(72.6)$ & $190(80.2)$ & \multirow{4}{*}{0.026} \\
\hline Mild (8-10) & $29(12.2)$ & $31(13.1)$ & \\
\hline Moderate (11-14) & $29(12.2)$ & $13(5.5)$ & \\
\hline Severe (15-21) & $7(3.0)$ & $3(1.3)$ & \\
\hline
\end{tabular}

A few patients did not complete all elements of the HADS so a score could not be calculated. $P$ values differ from those reported in text: analysis in text compares mean HADS scores using a $t$ test.

*Kruskal Wallis test. scale. The confidence interval for the number needed to treat was calculated using the Newcombe method, as implemented by confidence interval analysis software (BMJ Books, London). We considered a two tailed $P$ value of $<0.05$ as statistically significant. No interim analyses were planned or undertaken.

\section{RESULTS}

Between May 2006 and September 2007, 700 patients (349 intervention, 351 control) were recruited to the study (figure). An additional 167 patients (mean age 56.9 years, $89 / 167(53 \%)$ men) were also considered during this period: 32 declined participation, 19 had cognitive impairment and were unable to provide informed consent, 27 did not understand written English, 37 were either admitted for inpatient care or did not complete the chest pain unit's protocol, and details were missing for two. A further 50 patients were willing to join the trial but were excluded because the chest pain nurses thought that none of the information sheets was appropriate to their diagnosis. Also, four patients who agreed to participate had to be withdrawn before randomisation because of a sudden change in either their condition or the doctor's opinion.

The study population had a mean age of 48.6 years, and $61.6 \%(431 / 700)$ were men (table 1). Information sheets were deemed suitable for 19 patients with a diagnosis of angina (mean age 69, 58\% men), 162 with a diagnosis of definite benign non-cardiac pain (mean age $43,65 \%$ men), 61 with a diagnosis of uncertain cause requiring further cardiology investigation (mean age $52,49 \%$ men), and 458 with a diagnosis of uncertain cause suitable for expectant management (mean age $49,62 \%$ men).

The patients were sent a questionaire by post one month after recruitment; four were subsequently returned as the envelopes were incorrectly addressed. Responses were received from 494 patients (70.6\%): $248(71 \%)$ from the control group and $246(71 \%)$ from the intervention group.

Scores for anxiety and depression on the hospital anxiety and depression scale were both lower in the intervention group: anxiety 7.61 versus 8.63 (difference $1.02,95 \%$ confidence interval 0.20 to 1.84 , $\mathrm{P}=0.015)$, depression 4.14 versus 5.28 (1.14, 0.41 to $1.86, \mathrm{P}=0.002)$. On the anxiety subscale, intervention was associated with a shift from mild or moderate anxiety to no anxiety, whereas on the depression subscale, intervention was associated with a shift towards lower scores among those with no depression and also a reduction in the proportion with moderate depression (table 2). The number needed to treat to avoid one case of anxiety (the number of patients needed to be provided with an information sheet for one patient to move from a score of $\geq 8$ to a score of $\leq 7$ ) was 9.0 (95\% confidence interval 5.0 to 46.1$)$ and the number needed to treat to avoid one case of depression was 13.1 (6.6 to infinity)).

Patients in the intervention group had significantly higher scores for mental health $(\mathrm{P}<0.007)$ and general health perception $(\mathrm{P}<0.006)$ on the SF-36 than those in 
$\overline{\text { Table } 3 \mid \text { Mean (standard deviation) SF-36 scores in patients with acute chest pain randomised }}$ to receive verbal advice followed by an information sheet (intervention) or verbal advice alone

\begin{tabular}{lcccc} 
SF-36 items & Control group & Intervention group & Difference $(95 \% \mathrm{Cl})$ & P value \\
Physical functioning & $78.6(23.6)$ & $81.1(22.9)$ & $2.5(-1.7$ to 6.6$)$ & 0.239 \\
\hline Social functioning & $76.2(26.3)$ & $80.0(24.6)$ & $3.8(-0.7$ to 8.4$)$ & 0.095 \\
\hline Role physical & $65.1(41.1)$ & $70.8(39.3)$ & $5.7(-1.5$ to 12.9$)$ & 0.122 \\
\hline Role emotional & $65.8(41.8)$ & $70.8(38.8)$ & $5.0(-2.2$ to 12.2$)$ & 0.172 \\
\hline Mental health & $62.9(22.6)$ & $68.2(21.1)$ & $5.3(1.4$ to 9.2) & 0.007 \\
\hline Energy or vitality & $49.6(23.5)$ & $53.3(23.0)$ & $3.7(-0.4$ to 7.8$)$ & 0.079 \\
\hline Pain index & $69.2(26.1)$ & $72.8(25.9)$ & $3.6(-1.0$ to 8.2$)$ & 0.127 \\
\hline $\begin{array}{l}\text { General health } \\
\text { perceptions }\end{array}$ & $57.6(22.7)$ & $63.1(20.7)$ & $5.5(1.6$ to 9.3) & 0.006
\end{tabular}

the control group (table 3). There was also weak evidence that intervention was associated with higher scores for social functioning $(\mathrm{P}=0.095)$ and energy or vitality $(\mathrm{P}=0.079)$. Point estimates for all SF-36 dimensions were higher among patients receiving the information sheet.

Both groups had high scores for each dimension of patient satisfaction and there was no evidence that the information sheet was associated with any change in satisfaction with care (table 4). The prevalence of further pain did not differ: $40.4 \%(97 / 240)$ in the intervention group compared with $40.2 \%$ (97/241) in the control group (difference $0.2 \%, 95 \%$ confidence interval $-9.5 \%$ to $8.9 \%, \mathrm{P}=0.970)$; and there was no difference in the severity of pain experienced: 1.0 on a 0 - 10 scale in the intervention group compared with 1.1 in the control group $(0.1,-0.2$ to $0.4, \mathrm{P}=0.610)$.

There were no significant differences in the proportion of patients attempting changes in smoking, diet, or

\begin{tabular}{|c|c|c|c|c|}
\hline Dimension & Control group & Intervention group & Difference $(95 \% \mathrm{Cl})$ & $P$ value \\
\hline $\begin{array}{l}\text { Thoroughness of examinations and } \\
\text { accuracy of diagnosis }\end{array}$ & $4.24(0.86)$ & $4.21(0.92)$ & $0.04(-0.12$ to 0.19$)$ & 0.658 \\
\hline $\begin{array}{l}\text { Skill, experience, and training of } \\
\text { hospital staff }\end{array}$ & $4.31(0.72)$ & $4.25(0.87)$ & $0.06(-0.08$ to 0.20$)$ & 0.407 \\
\hline Thoroughness of treatment & $4.29(0.78)$ & $4.33(0.87)$ & $0.04(-0.10$ to 0.19$)$ & 0.550 \\
\hline $\begin{array}{l}\text { Explanations about medical } \\
\text { procedures and tests }\end{array}$ & $4.16(0.92)$ & $4.18(0.94)$ & $0.02(-0.14$ to 0.18$)$ & 0.802 \\
\hline $\begin{array}{l}\text { Attention given to what you have to } \\
\text { say }\end{array}$ & $4.02(0.93)$ & $4.06(0.99)$ & $0.04(-0.13$ to 0.21$)$ & 0.672 \\
\hline $\begin{array}{l}\text { Advice about ways to avoid illness } \\
\text { and stay healthy }\end{array}$ & $3.46(1.22)$ & $3.62(1.17)$ & $0.17(-0.05$ to 0.38$)$ & 0.126 \\
\hline $\begin{array}{l}\text { Friendliness and courtesy shown by } \\
\text { hospital staff }\end{array}$ & $4.51(0.71)$ & $4.40(0.78)$ & $0.11(-0.02$ to 0.24$)$ & 0.096 \\
\hline $\begin{array}{l}\text { Personal interest in you and your } \\
\text { medical problems }\end{array}$ & $4.08(0.95)$ & $4.08(0.92)$ & $0.00(-0.17$ to 0.17$)$ & 0.997 \\
\hline Respect and attention to privacy & $4.19(0.96)$ & $4.14(0.97)$ & $0.05(-0.12$ to 0.22$)$ & 0.547 \\
\hline $\begin{array}{l}\text { Reassurance and support offered by } \\
\text { hospital staff }\end{array}$ & $4.11(0.95)$ & $4.11(0.97)$ & $0.01(-0.16$ to 0.18$)$ & 0.933 \\
\hline $\begin{array}{l}\text { Amount of time hospital staff gave } \\
\text { you }\end{array}$ & $3.85(1.03)$ & $3.91(1.00)$ & $0.06(-0.12$ to 0.23$)$ & 0.541 \\
\hline Overall quality of care & $3.56(0.60)$ & $3.52(0.66)$ & $0.03(-0.08$ to 0.14$)$ & 0.566 \\
\hline
\end{tabular}

exercise: $42.9 \%(36 / 84)$ of smokers in the intervention group attempted to stop compared with $43.0 \%$ (43/ $100)$ in the control group $(0.1 \%,-14.0 \%$ to $14.2 \%$, $\mathrm{P}=0.984), 69.5 \%(157 / 226)$ in the intervention group attempted to change their diet compared with $70.9 \%$ $(161 / 227)$ in the control group $(1.5 \%,-6.9 \%$ to $9.8 \%$, $\mathrm{P}=0.318)$, and $65.5 \%(150 / 229)$ in the intervention group attempted to increase their exercise compared with $63.5 \%(146 / 230)$ in the control group $(2.0 \%$, $-6.7 \%$ to $10.7 \%, \mathrm{P}=0.728)$.

Some patients sought further information on their symptoms from more than one source (table 5). Provision of the information sheet was associated with no significant difference in information seeking from any source. There was no evidence that the information sheet altered planned action in the event of recurrent pain: $57 \%$ (134/234 patients) in the intervention groups would call for an emergency ambulance compared with 58\% (139/238) in the control group, 24\% (56) compared with $23 \%$ (54) would attend their general practitioner, 10\% (24) compared with $9 \%$ (21) would take analgesics, $2 \%$ (4) compared with 3\% (6) would ignore the pain, and 7\% (16) compared with $8 \%(18)$ would take another course of action $(\mathrm{P}=0.937)$.

\section{DISCUSSION}

Provision of written information to patients with acute chest pain can reduce anxiety and depression and improve mental health and general health perception, but it does not alter the frequency or severity of further pain, plans for changes to lifestyle, subsequent information seeking behaviour, planned actions in response to further pain, or patient satisfaction with care. The differences in scores on the hospital anxiety and depression scale recorded in this study border on being clinically important and may represent worthwhile benefits for patients. As the information sheets are simple to administer and outcomes were on balance positive, we recommend their use in patients receiving diagnostic assessment for acute chest pain.

In making this recommendation several caveats should be borne in mind. The information sheets were developed, validated, and evaluated in English speaking patients in a northern English city with a relatively small ethnic minority population. The sheets may need modification to take into account language, social, and cultural differences between the study setting and other locations. Specialist chest pain nurses administered the information sheets and provided verbal advice, so the sheets should augment rather than replace verbal advice with an experienced clinician.

\section{Comparison with previous studies}

Previous evaluations of written information in the emergency department have produced mixed results. One study ${ }^{12}$ found that providing information on the function of the emergency department and times to the evaluation of patients on alternate days was associated with improved patient satisfaction. Another study ${ }^{13}$ found that introduction of an information leaflet was associated with improved satisfaction. However, 
Table 5|Proportions of patients with acute chest pain randomised to receive verbal advice followed by an information sheet (intervention) or verbal advice alone who sought further information. Values are numbers (percentages) unless stated otherwise

\begin{tabular}{lcccc} 
Variables & Control group & Intervention group & Difference $(95 \% \mathrm{Cl})$ & $\mathbf{P}$ value \\
General practitioner & $123 / 225(55.7)$ & $103 / 223(46.2)$ & $8.5(-0.8$ to 15.5$)$ & 0.073 \\
\hline Hospital & $64 / 196(32.7)$ & $55 / 198(27.8)$ & $4.9(-4.2$ to 13.8$)$ & 0.292 \\
\hline Friends or family & $53 / 183(29.0)$ & $54 / 188(28.7)$ & $0.2(-8.9$ to 9.4$)$ & 0.960 \\
\hline Books or magazines & $46 / 184(25.0)$ & $43 / 186(23.1)$ & $1.9(-6.8$ to 10.6$)$ & 0.672 \\
\hline Telephone advice line & $7 / 173(4.0)$ & $8 / 176(4.5)$ & $0.5(-4.1$ to 5.2$)$ & 0.818 \\
\hline Any source & $171 / 240(71.3)$ & $165 / 240(68.8)$ & $2.5(-5.7$ to 10.6$)$ & 0.550 \\
\hline
\end{tabular}

patient satisfaction was unchanged in a study ${ }^{14}$ that undertook allocation of an emergency department to provision of an information leaflet in two week clusters. Our study found no improvement in satisfaction associated with provision of the information sheet. One possible explanation is that satisfaction levels were high in the control group, with care being rated as "very good" on average, so there was little scope for the information sheet to produce improvement. Alternatively, it is possible that the information sheets were not optimal and that a less clinically focused information sheet or one with a different format would have achieved higher levels of satisfaction and behavioural change.

Information sheets relating to cardiac diagnostic assessment have received little evaluation. A small randomised trial ${ }^{15}$ on methods for providing information to outpatients undergoing exercise treadmill testing showed that provision of a written pamphlet resulted in fewer episodes of chest pain over the following month. Higher levels of reassurance were achieved when the pamphlet was combined with a brief discussion about the meaning of normal test results.

Systematic reviews of written information in other conditions have produced mixed findings. One review $^{16}$ identified only two trials of written information for patients being discharged from acute hospital settings to home. They showed increased knowledge and improved satisfaction associated with written information for parents of children discharged from children's hospitals. Another review ${ }^{17}$ found that provision of written information on medicines did not generally increase knowledge or improve satisfaction, although this could have reflected the poor quality of the leaflets tested. One study ${ }^{18}$ found that provision of information for patients with stroke and their carers using a variety of methods was associated with improved knowledge and satisfaction and a small reduction in depression.

\section{Limitations}

We were unable to blind patients to treatment group so questionnaire responses may have been influenced by awareness of intervention received. We originally planned to use a postponed informed consent procedure, ${ }^{19}$ whereby patients would be asked to consent to having full information withheld about the study (particularly the exact nature of the intervention) until after follow-up. The ethics committee did not, however, approve this suggestion. There is also potential for contamination between the intervention and control groups by nurses learning the information provided on the information sheet and giving this verbally to the control group. If contamination were a problem we would anticipate that this would attenuate the observed effect of the information sheet. We excluded patients with important comorbidities, cognitive impairment, and inability to understand written English, so the findings may not be generalisable to all patients with chest pain. Finally, just under $30 \%$ of the study population did not respond to the questionnaire and thus provided no outcome data. Response rates in the two study arms were almost identical, so there was no evidence of differential responses leading to bias.

\section{Unanswered questions and future research}

One feature of our evaluation that warrants further comment is that most patients received the information sheet on the basis of a diagnosis of pain of uncertain cause suitable for expectant management. This is a surprising finding and suggests that the diagnostic assessment may not be as decisive as we might like. Alternatively, it may reflect reluctance to categorise patients with a negative diagnostic assessment as having definite non-cardiac pain, particularly when a less decisive option (uncertain cause) is available. A recent study of 8762 patients diagnosed as having benign chest pain in a cardiology clinic $^{20}$ found that $2.7 \%$ died of coronary heart disease or had an episode of acute coronary syndrome or unstable angina over the following three years. This suggests that it is probably appropriate to admit uncertainty after a negative diagnostic assessment.

Given the potential benefits we have shown from provision of an information sheet for patients with chest pain, further research would be worthwhile to develop and evaluate written information for other conditions that are associated with significant patient anxiety and impaired quality of life. In the case of chest pain, further research is required to adapt information sheets for non-English speaking patients.

\section{WHAT IS ALREADY KNOWN ON THIS TOPIC}

Acute chest pain is common and often associated with anxiety and impaired quality of life despite a thorough diagnostic assessment

Written information can assist with communication after assessment for acute chest pain

\section{WHAT THIS STUDY ADDS}

An information sheet for patients with acute chest pain can reduce anxiety and depression and improve mental health and general perception of health

The information sheet did not alter subsequent symptoms, lifestyle change, information seeking, planned actions in the event of further pain, or patient satisfaction 
We thank chest pain nurses Karen Angelini, Nicola Connell, Lesley Lowe, Aliceson Minto, Melanie Stevens, and Adele Wright for obtaining patients' consent, and Margaret Jane for clerical assistance.

Contributors: SG provided the original idea for the study, analysed the data, and is guarantor. JA, SG, PB, and JP designed the study. JA collected the data. All authors contributed to writing the paper and approved the final draft.

Funding: JA was supported by a Health Foundation Leadership through Practice Award. The funders played no part in the study design, the collection or analysis of data, the writing of the report, or the decision to submit for publication. All the authors are independent of the funders. Competing interests: JP has received research grants and honorariums from Servier UK.

Ethical approval: This study was approved by the north Sheffield local research ethics committee.

1 Goodacre S, Cross E, Arnold J, Angelini K, Capewell S, Nicholl J. The health care burden of acute chest pain. Heart 2005;91:229-30.

2 Fleet RP, Dupuis G, Marchand A, Burelle D, Arsenault A, Beitman BD. Panic disorder in emergency department chest pain patients: prevalence, comorbidity, suicidal ideation and physician recognition. Am J Med 1996;101:371-80.

3 Yingling KW, Wulsin LR, Arnold LM, Rouan GW. Estimated prevalences of panic disorder and depression among consecutive patients seen in an emergency department with acute chest pain. J Gen Intern Med 1993;8:231-5.

4 Goodacre S, Mason S, Arnold J, Angelini K. Psychological morbidity and health-related quality of life of patients assessed on a chest pain observation unit. Ann Emerg Med 2001;38:369-76.

5 Price JR, Mayou RA, Bass CM, Hames RJ, Sprigings D, Birkhead JS. Developing a rapid access chest pain clinic: qualitative studies of patients' needs and experiences. J Psychosom Res 2005;59:237-46.

6 Arnold J. Leading practice through research award final report. London: Health Foundation, 2008.

7 Zigmond AS, Snaith RP. The hospital anxiety and depression scale. Acta Psychiatr Scand 1983;67:361-70.

8 Ware JE, Snow KK, Kosinski M, Gandek B. SF36 health survey: manual and interpretation guide. Boston, MA: Health Institute, New England, 1993.
9 Davies AR, Ware JE. The GHAA consumer satisfaction survey and users manual. Washington DC: Group Health Association of America, 1991.

10 Goodacre SW, Quinney D, Revell S, Morris F, Capewell S, Nicholl J. Patient and primary care physician satisfaction with chest pain unit and routine care. Acad Emerg Med 2004;1:827-33.

11 Goodacre S, Nicholl J, Dixon S, Cross E, Angelini K, Arnold J, et al. Randomised controlled trial and economic evaluation of a chest pain observation unit compared with routine care. BMJ 2004;328:254-7.

12 Krishell S, Baraff LI. Effect of emergency department information on patient satisfaction. Ann Emerg Med 1993;22:568-72.

13 Kologlu M, AgalarF, Cakmakci M. Emergency department information: does it affect patients' perception and satisfaction about the care given in an emergency department? Eur J Emerg Med 1999;6:245-8.

14 Sun BC, Brinkley M, Morrissey J, Rice P, Stair T. A patient education intervention does not improve satisfaction with emergency care. Ann Emerg Med 2004;44:378-83.

15 Petrie KJ, Muller JT, Schirmbeck F, Donkin L, Broadbent E, Ellis Cl, et a . Effect of providing information about normal test results on patients reassurance: randomised controlled trial. BMJ 2007;334:352-4

16 Johnson A, Sandford J, Tyndall]. Written and verbal information versus verbal information only for patients being discharged from acute hospital settings to home. Cochrane Database Syst Rev 2005;(3):CD003716.

17 Raynor DK, Blenkinsopp A, Knapp P, Grime J, Nicolson DJ, Pollock K, et al. A systematic review of quantitative and qualitative research on the role and effectiveness of written information available to patients about individual medicines. Health Technol Assess 2007;11(5):1-178.

18 Smith J, Forster A, House A, Knapp P, Wright JJ, Young J. Information provision for stroke patients and their caregivers. Cochrane Database Syst Rev 2007;(3):CD001919.

19 Boter H, van Delden JJM, de Haan RJ, Rinkel GJE, for the Home Evaluation of Stroke Induced Aid Study Group. Modified informed consent procedure: consent to postponed information. BMJ 2003;327:284-5.

20 Sekhri N, Feder GS, Junghans C, Hemingway H, Timmis AD. How effective are rapid access chest pain clinics? Prognosis of incident angina and non-cardiac chest pain in 8762 consecutive patients. Heart 2007;93:458-63.

Accepted: 19 November 2008 